\title{
The preeminence of clusters
}

\author{
Many cities and countries still view the foundation of a biotech sector as desirable for a high-tech, intellectually \\ driven economy. But a discussion by seasoned biotech management and investors suggests that attaining an \\ environment with the right mix of money, management and innovation remains a difficult and long-term challenge.
}

\begin{abstract}
ocation is interwoven with the ability of -biotech startups to prosper. Regions with nascent biotech sectors often find attracting the necessary financial and human resources to their area an uphill struggle, which can mean the difference between success or failure for a fledgling life science business. In the following article, a group of experienced biotech executives and investors from around the world discuss the pros and cons of building a business inside or outside a cluster. The article is an abridged transcript of a Bioentrepreneur roundtable discussion held at the Marriott Boston Copley Place; it was convened at the Biotechnology Industry Organization International Convention in Boston, May 5, 2007. It has been edited to address the major themes of that discussion.
\end{abstract}

\section{How important is location in the success or failure of a biotech enterprise?}

Pratik Shah: If I had any advice for an entrepreneur who's looking to start up a biotech not located in a cluster, it would be: "Move to the nearest biotech cluster." There has to be a really compelling reason not to do so. And it has to have something to do with a core competitive advantage that staying in the current location is giving them.

Fritz Bühler is at the European Center of Pharmaceutical Medicine, University Hospital, CH-4031, Basel, Switzerland; C. Mark Tang is at World Technology Ventures, LLC, 14 Wall Street, 20th Floor, New York, New York 10005, USA; Pratik Shah is at Thomas, McNerney \& Partners, One Market, Steuart Tower, Suite 1030, San Francisco, California 94105, USA; Mark Leuchtenberger is at Targanta Therapeutics, 222 Third Street, Suite 2300, Cambridge, Massachusetts 02142, USA; Ko-Chung Lin is at 13F, No. 3 YuanQu St., Nankang Dist., Taipei 115, Taiwan; Pedro de Noronha Pissarra is at Biotecnol SA, Lagoas Park, Edifício 7, 2741-901 Porto Salvo, Oeiras, Portugal.

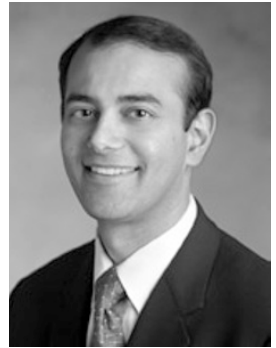

Pratik Shah is partner at Thomas, McNerney \& Partners are going to create products? If the answer is the former, then there are models that have recently emerged in the United States. For example, Florida has set up the Scripps Research Institute with a significant allocation of government funding to get it up and running, and I presume the goal there is to create sustainable research that will attract NIH dollars. But that's a little bit of a zero-sum game. If the objective is to create products, then there is a fundamental gap, because allocation of dollars is not enough. Without involvement of experienced, professional investors who know exactly what kind of things will get funded down the road, it's hard to create an organization that's really ready for that next level of funding without having an active collaboration or dialog or, in the ultimate sense, a very close partnership with the professional investors who are going to take those companies to the next level.

Pedro de Noronha Pissarra: With clusters, at Biotecnol we personally have a geographical problem. Nobody would invest in Portugal, where we are based. So for that reason, we set up a unit in Maryland, and we started doing our deal-making through the Maryland company, Biotecnol Inc., and the whole thing developed very nicely.

But we're still not quite in the cluster, and

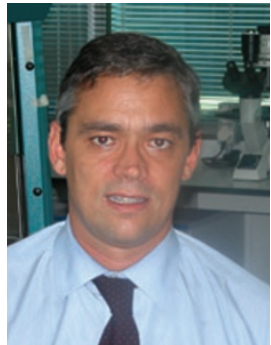

Pedro de Noronha Pissarra is CEO of Biotecnol. attracting top-tier management is a problem. It's not qualified people, because there are many qualified people around that went to Ivy League universities, or went to Oxford and Cambridge in the UK. But it's really hard to find the top-notch manager that will see us to the next stage.

So I would say one thing: Don't start the company in a place that is not a cluster! Portugal is a great place. I love it. I lived, worked, and studied abroad for many years and then went back because of the fantastic lifestyle. But, at the end of the day, you've got to be on a plane every month, going to biotech clusters, delivering your talks, convincing people that while we've got great wines and great food in Portugal, we also do great things in Biotech. It was initially a very hard sell, but since we have grown and have created a recognized and successful buisness, perception about us has definitely changed. But we need more examples of success.

Mark Leuchtenberger: When I was recruited to

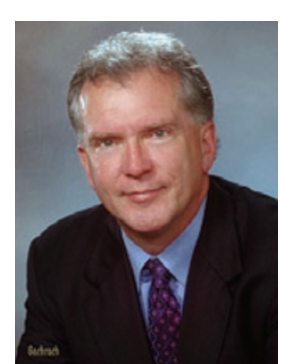

Mark Leuchtenberger is president and CEO of Targanta Therapeutics. Targanta [in the summer of 2006], they said they had a great drug with two positive phase 3 trials, and said the company is located in Indianapolis. I said, "Well, my geography is here, I've spent twenty years here, and I'm not moving." And they said, No, we're not expecting the CEO to move to Indianapolis. 
Essentially they were doing this search while acknowledging that Indianapolis might be like Pedro's description of Portugal. It was going to be a place where you could do R\&D, but you might set up a commercial or investment headquarters somewhere else - either San Francisco, or La Jolla, or Baltimore, or Boston, but not Indianapolis. You don't think biotech is regional, but, because of the companies and investors, it's intensely regional. People don't want to have to fly if they don't have to.

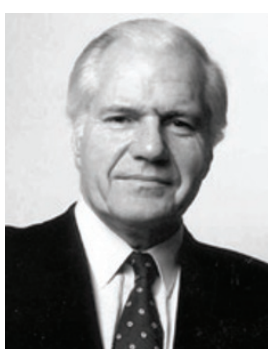

Fritz Bühler is director of the European Center of Pharmaceutical Medicine and professor of pharmaceutical medicine \& pathophysiology at University Hospital, Basel, Switzerland, and partner in Bear Stearns Health Innoventure.

now. What are we going to do now? Are we going to spin-off the products completely to the Maryland subsidiary and Biotecnol Portugal is a shareholder, are we going to raise funds and hire local teams so it actually ends up being a spin-off of the company? I see your point; it's very valid. And it's already creating a lot of questions, so people are saying, "We are investing where? Where are the shareholders, where is the management?"

\section{Beyond easy access to venture capital and infrastructure, why are clusters so important?}

ML: Take the Boston area. I think in the past five or six years or so, Novartis [Basel], Pfizer [New York], Merck [Whitehouse Station, New Jersey], Wyeth [Madison, New Jersey] and Bristol-Myers [Princeton, New Jersey], most recently, have all voted with their feet to come here. I think of it sort of as a casino: the house always wins. By that I mean the house is the resident group of knowledgeable, able managers and scientists. Projects come and go, and sometimes you are out of work for months, but usually you just keep participating and don't have to uproot your family. A lot of people switch jobs in Cambridge and don't

even change their commute except for the last 200 feet. There are 50 companies over there!

I think that this is what people are betting their careers on now: serial entrepreneurship, over and over again. I've been doing that for the past five years-some of it works out pretty well and some of it works out pretty badly, but here's the bottom line: you're probably staying in the same location, you're accruing a group of people you trust who you can work with, and hopefully you're accruing the trust of the venture capitalists so that when another good idea comes up, they think of you and hopefully you can participate.

PS: I need you to talk to the CEOs of my companies that have only one product. They're always trying to in-license something for job security, and I say, "Hey you're in a cluster. You're going to be fine."

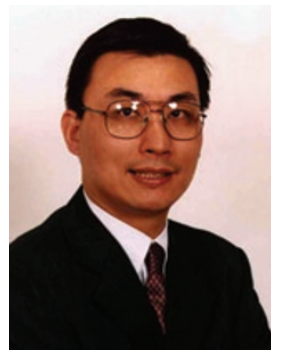

C. Mark Tang is managing director and chairman, World Technology Ventures. the reason why big pharma and biotech are here in Boston-because of Harvard, the Massachusetts Institute of Technology, etc.

\section{In what ways are countries with nascent sectors attempting to foster biotech?}

CMT: I'll just explain China as an example of Asia. Typically what China has is the government funding. For example, Ministry of Science and Technology, among other agencies, has grants it can fund research and development of startups with, and the city usually has some fund, and then certain banks do too. The government-owned high tech parks at times provide biotech the incubator space perhaps for free or at a discount for a couple of years and perhaps some seed/ grant money for free as well. But there are not many, if any, Western style venture capital [VC] firms or groups for biotech. I once invited a well-known VC firm from the US to China to speak at a conference I organized. The VCs were very excited about the prospect of the industry after seeing high tech park and want to open an office perhaps in five years. But still, biotech is very new.

PS: I'm curious, are there more examples of countries like Singapore who've said that they're taking a very long-term view and allocating a billion-plus dollars in capital toward biotech? And fundamentally from an infrastructure standpoint, is there really a logical reason that biotech should be there as opposed to some other Asian region? That is a positive example of a government making a long-term financial commitment to try to create a cluster.

CMT: I've been to Singapore a few times and I know a couple of managers of the biomedical fund as well. I think the strategy of Singapore is good. They want to form a biotech cluster. Mainly the money they invested in the beginning had a few strings attached, such as giving them first rights of refusal in Asia. So essentially what they were doing was investing money in technology and products overseas and buying Asian rights, and, in turn they're going to sell those products to the Malaysians, to the Indians and to China.

What's happening in Asia, I believe, is that Singapore is a role model because they have managed to set this up in very powerful way, put the right funds behind it and attract even buy top people even a Nobel Prize Laureate from around the world to work and live there.

But in China, as well as other Asian nations, I'm worried whether there are funds available now to do this similar (approach) to Singapore? Of the main Chinese biotech centers, Beijing, Shanghai are very good. The next group is TianJing and Shenzhen. One should not forget that the Western Hemisphere, led by the United States, has an enormous advantage and is ahead by 20 years compared with Asia. I don't think one has to reinvent the wheel. Just take the best from what we have learned in developing biotech regions in the United States and Europe, and then insert that in an orchestrated way in Asia, taking advantages of lost-cost, high quality human resources and emerging large local market there.

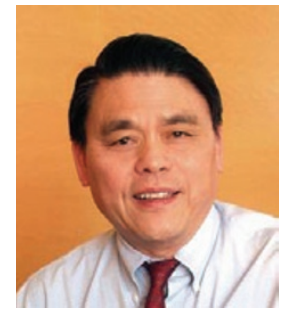

Ko-Chung Lin is chairman and CEO of PharmaEssentia.
Ko-Chung Lin: When I deal with Asian companies, I tell them, "You know, if you want to get money from the US you've got to register yourself in the US." I work with people who are actually registered here, but in reality it's virtual-no one is really based here, everyone is in China. But it appears to be a global company, and this makes US investors feel comfortable. Especially in New 
York, where there are large funds and they have a percentage that have to invest internationally, so they're very active in looking overseas. Of course, the key part is you've got to have a good story. You know biotech: you don't have to be making money.

PS: I guess the real question is how many venture dollars are flowing into those regions, and if the answer is not a lot, then I think the writing is on the wall. Because although many countries are vying for life scienceoriented venture funds, is biotech really for every region? Is there really a fundamental reason why biotech should be in a particular geography where it already isn't? I would take a really cold, hard look at what the facts are.

\section{What types of business models and exits can biotechs around the world offer investors?}

CMT: Like US, there are four-five business models in China: reagent, equipment and services; generic drugs; technology platform; R \& D products and hybrid of technology and products. Right now, service companies, such as contract research organizations, and generic companies are hot in China. Several of them have raised money through IPOs in US stock exchanges.

FB: Valuations have changed enormously over the past ten years. Obviously once you have an asset you want to let it grow as much as possible, so probably the best point at which to sell or partner is after a proof of concept, and it seems possible to develop any compound up to proof of concept. So I think the time is over for any garden-variety investor; it's now smart money. I believe that the funds have changed greatly in the sense that they are now run by people from the pharmaceutical industry who bring not only the dollars, but smart dollars to the table.

The initial public offering [IPO] situation is another major problem, but one well solved in the United States with the NASDAQ exchange, and poorly solved in Europe or in other parts of the world. There are plenty of stock exchanges, but none really have the right flow or a big enough float, and the situation is so scattered in Europe that it's really difficult to go through a successful IPO. It does still happen, despite this scattering, and one wishes that there would be more concentrated IPOs, but nationalism is a huge problem. Why should you, as a Viennese, invest in Zurich? Or a UK person invest in someplace besides London?
PS: I recently looked at the number of companies that were venture backed that had liquidity events driven by IPOs versus mergers and acquisitions [M\&A] in the past three years, with a cut-off of $\$ 300$ million exit value or greater in biotech, pharmaceuticals and medical devices. The numbers suggested that the two paths led to roughly equal numbers of exit opportunities. So, yes there has been a lot of buzz about M\&A because of the recent flurry of activity, but I still think that the other path exists; it's certainly nowhere near the valuations that it used to be and therefore has really created a situation in which the amount of the capital and the pre-money valuations that private investors have to make work is much more constrained. I think the two paths still exist.

FB: I'm not sure that the IPO window is totally closed. There's still some happening, particularly in Europe, although the M\&A pathway is the one that is now favored. There again, one should caution the biotech/ pharma small companies not to merge or be acquired too early, but really grow their value. Unfortunately, that doesn't always happen because of the enormous pressure being exerted by the pharma world, which is short of good ideas and compounds. There's also an innovation gap and a development gap-so pharma really gets its arms around everything it can find.

PNP: The hybrid model should help with valuations, but it's a very hard sell. To say, Okay, we have excellent development capabilities, we may have worked with ScheringPlough [Kenilworth, New Jersey], with Sanofi-Aventis [Paris] or whomever, but still it doesn't sell because the model is capped. The service company will always be the less attractive thing for the investor. I know Pratik has a service company in his portfolio, but he's one of the very few venture capitalists that I know that has that. So you've got to separate the businesses completely. And this puzzles me because it's a perfect meeting of the two worlds; you can mitigate the risk, you even have nice revenues, you've got granted patents on valuable products and technologies, among great know-how, but when you put the two models together, people don't generally like to invest in such structure. Why? I am not certain, but I am convinced that since we favored a product development oriented strategy we certainly have created a great deal of interest in the investment community.
KCL: I can explain this to you. The problem has two parts. The service guy says, I don't want to do drug development because I'm always losing money; the drug development guy says, I want a high-risk return, and I don't like service. So, when you put them together, very few people want to do it. Another problem is working with partners. Because you are working with big pharma, they give you projects to do services on, and they're scared that you're passing these things on to your idea unit or going around them. So pharma says, Listen, if you want to do drug development, you're not going to get our contract. If you shut down your drug development, then we'll give it to you. Because this product is so important to us, you know we've spent hundreds of millions of dollars, we're not going to give it to you if you have an idea unit.

ML: I've got a Biogen [Cambridge, Massachusetts] analogy from the early nineties. We were going along, scraping by, but we signed this deal, got a little bit of money in, and then all of a sudden the hepatitis B and alpha interferon royalties started to kick in and our royalty revenue went from $\$ 60$ million to $\$ 70$ million in 1991 to $\$ 135$ million in 1992. Suddenly we had money to fund all our own development. Did the investment stock market like it? No, they hated it! It was like it was a service business. It was pure royalty; it was pure profit, but they looked and they said, What are you doing with it? You have boring royalties that are only going to increase a certain amount, and until then you're nothing more than a royalty trust and a boutique and a bunch of airheads walking around talking about things.

PS: But that's actually not as irrational a financial decision as it sounds. Look at Biogen versus Amgen [Thousand Oaks, California]; they were started at roughly the same time, and, if you look at those companies' market caps from when they were started or when they went public to today, you see that there's a long period when Biogen's market cap is basically flat, whereas Amgen was favored by Wall Street. Why is that? Well you could call it brilliance or you could call it just luck. But if you have a specialty product where you can develop a sales force, you're going to make a lot higher margin on a lot lower sales line than a royalty model. That's why the market caps diverged. I think that the fundamental issue of market appreciation comes down to, how much are you really going to be able to derive from the pipeline? 